\title{
Proceedings of the 2011 MidSouth Computational Biology and Bioinformatics Society (MCBIOS) Conference
}

\author{
Jonathan D Wren ${ }^{1 *}$, Doris M Kupfer ${ }^{2}$, Edward J Perkins ${ }^{3}$, Susan Bridges ${ }^{4}$, Stephen Winters-Hilt ${ }^{5}$, \\ Mikhail G Dozmorov', Ulisses Braga-Neto ${ }^{6}$ \\ From Eighth Annual MCBIOS Conference. Computational Biology and Bioinformatics for a New Decade \\ College Station, TX, USA. 1-2 April 2011
}

\section{Introduction}

The Eighth Annual Conference of the MidSouth Computational Biology and Bioinformatics Society (MCBIOS'2011) was held in College Station, Texas on April 1-2, 2011. The Conference General Chair was Ulisses Braga-Neto, the MCBIOS President for the 2010-2011 term, from Texas A\&M University. There were nearly 200 registrants and 140 abstracts were submitted, divided into 48 oral presentation abstracts and 92 poster session abstracts.

In addition, participants attended talks by very distinguished Keynote speakers. Joan W. Bennett, from Rutgers University and Member of the National Academy of Science, presented the talk "Chromosomal Composition and Computational Competence;" Donald Geman, from The Johns Hopkins University and co-inventor of the Gibbs Sampler and Random Forest Classifiers, lectured on "Measuring Network Regulation and Differential Expression by Rank Conservation;" while John Weinstein, Chair of the Department of Bioinformatics and Computational Biology at the University of Texas M.D. Anderson Cancer Center, talked on "Personalizing Cancer Medicine in the Era of Next-Generation Sequencing: Omics and Informatics."

The conference also benefited from invited dinner and lunch speakers, who gave informal, highly informative and entertaining talks. Edward R. Dougherty, from Texas A\&M University and Director of Computational Biology at the Translational Genomics Institute, asked the audience "Is Biological Science Delightful?" whereas

\footnotetext{
* Correspondence: jdwren@gmail.com

${ }^{1}$ Arthritis and Immunology Research Program, Oklahoma Medical Research

Foundation; 825 N.E. 13th Street, Oklahoma City, OK 73104-5005, USA

Full list of author information is available at the end of the article
}

Ernesto Marques, from the Center for Vaccine Research at the University of Pittsburgh, gave the talk "Activation of the Complement System in Dengue Infection: Opportunities for Computational Modeling."

Participants also had the opportunity to attend handson workshops on NCBI tools, presented by Peter Cooper from NCBI/NIH, and on protein evolution, presented by Hugh Nicholas and Troy Wymore, from the Pittsburgh Supercomputing Center. The winners of conference awards were:

\section{Best Oral Presentations (students):}

First place: Suzanne Matthews, Texas A\&M University Second place (3-way tie): Lori Dalton, Texas A\&M University

Second place: Shelton Griffith, Oak Ridge National Lab

Second place: Winston Haynes, Hendrix College

Best Oral Presentations (Post-Doctoral fellows):

Yan Li, NCTR

Fan Zhang, IUPUI

Best Poster (Computation):

First place: Tianchuan Du, Southern University

Second place: Christopher Cathey, Jackson State University

Third place: Ralph Crosby, Texas A\&M University

Best Poster (Biology):

First place: Awantika Singh, UALR/UAMS

Second place: Mohammed Shahrokh Esfahani, Texas A\&M University

Third place: Fang-Han Hsu, Texas A\&M University

MCBIOS Outstanding Service Award: Dr. Jonathan D. Wren, Oklahoma Medical Research Foundation

C 2011 Wren et al; licensee BioMed Central Ltd. This is an open access article distributed under the terms of the Creative Commons 


\section{Proceedings summary}

Accepted for publication in the conference proceedings for this year were 21 research manuscripts out of a total of thirty three papers submitted for consideration ( 64\%). The volume of papers dropped a bit from last year's record-setting forty-three papers submitted and twenty eight accepted [1-28], yet the acceptance rate was very similar. At least 2 reviewers, a mixture of external and internal (i.e., MCBIOS members), were responsible for evaluating each paper. Our goal for inclusion of papers in the conference proceedings remains the same as prior years: To be inclusive, yet rigorous in the peer-review process such that accepted papers are both high quality and reflective of the work presented at the conference. Papers generally fell into five categories:

\section{Genomic analysis}

Michael Mayo et al. propose a one-dimensional diffusion-reaction model, in the form of a master equation, to analyze the non-equilibrium protein sliding kinetics along a segment of bacterial DNA [29]. Model validity is assessed through Monte Carlo simulations, and the results are interpreted within the context of bacterial transcription.

Sujoy Roy et al. describe a novel method to identify potential transcription factors from a list of differentially expressed genes using textual similarity between the genes and transcription factors reported in the literature [30]. Importantly, their approach has the potential to identify transcription factors that might be indirectly regulating the genes and, thus, would not be recognized by sequence-based analysis of the expressed gene promoters.

In "An Efficient and Extensible Approach for Compressing Phylogenetic Trees" [31], the authors demonstrate an efficient method for compressing large collections of Newick file representations of phylogenetic trees. To do this, the Newick file compression is directly operated on, without decompression needed.

\section{Network analysis}

Ying Li et al. describe RefNetBuilder [32], a platform for the construction of putative reference pathways or gene regulatory networks from expressed sequence tags (ESTs), which provides a bioinformatics tool for researchers who work with non-model organisms.

Analyses of gene expression networks require understanding of how these networks can be manipulated to achieve desirable phenotype. The paper by Noushin Ghaffari et al.[33] proposes an alternative method for devising intervention/control policies for Boolean networks. Not only does it outperform other available techniques (MFPT-CP and SSD-CP) but eliminates the step of network reduction, thus simplifying analysis of large gene regulatory networks without loss of information.

Mohammad Shahrokh et al. [34] describe an algorithm for identifying a set of mutations that drove a healthy network into a cancerous state. Based on partial knowledge of the underlying gene regulatory network and the steady state distribution of the gene expression values in a given tumor, their algorithm is able to reconstruct the actual path of tumor progression in simulated and real networks.

\section{Systems biology}

Fan Zhang and Jake Chen develop a repository for human organ-specific biomarkers called HOMER [35]. The ability to distinguish the tissue-specificity or enrichment of individual proteins is an important step in being able to define, molecularly, what is "normal" versus diseased and opens up avenues to use these patterns for diagnostics.

Xiaoning Qian and collaborators describe an improved method for computing the similarity between nodes when aligning different biological networks [36]. A semi-Markov random walk framework is used to calculate global correspondence scores between all pairs of nodes in the networks. The effectiveness of the approach in recovering known pathways is demonstrated with both synthetic and microbial networks.

Venkata Swamy and colleagues [37] describe a k-votes method for integrating protein-protein interaction (PPI) networks constructed from different databases. Edges are included in the integrated network if they are included in at least $\mathrm{k}$ of the source networks. The authors evaluate the "goodness" of the resulting network for different values of $k$ by clustering the integrated network and evaluating the resulting clusters using measures of modularity, similarity-based modularity, clustering score, and enrichment in biological annotations. Results indicate that a k-value of two provides the best results.

Emerging biological threats or epidemics can rapidly spread through out the world due to readily accessible and rapid transportation systems. Social networking data, news, and databases where hospitals and clinical laboratories deposit screening data world wide can be harnessed to assess potential outbreaks of human pathogens. Researchers at Oak Ridge National Laboratories [38] outlined a strategy for Biological Signature Identification and Threat Evaluation System (BioSITES). The authors focused on the principles for constructing a semantic knowledgebase capable of integrating diverse data repositories and data streams to use in constructing such a threat identification system.

\section{Microarray studies/RNAseq}

With thousands of microarray experiments publicly available, researchers are increasingly interested in 
conducting meta-analyses of them, yet finding a way to make each dataset directly comparable is challenging because of the technical and experimental variation. To solve this, Dozmorov and Wren report on a semi-automated method to normalize thousands of microarray experiments from NCBI's GEO database, to create a standardized subset of many or even all experiments [39]. Once these datasets can be directly compared, the authors also show that a meta-analysis of gene-gene coexpression patterns across 1 -color microarrays can be used to accurately predict gene ontology categories [40]. In addition to enabling topic-centric transcriptional meta-analyses, global meta-analysis of gene-gene coexpression patterns has also been shown to be useful in predicting function and phenotype for genes [41,42].

Minjun Chen et al. from the Food and Drug Administration present an assessment of models to find biomarkers from microarray experiments that are predictive of clinical endpoints [43]. They find that an ensemble method (i.e., using a combination of results from different methods) outperforms expert-nominated models.

As the cost of sequencing declines, RNAseq is poised to replace microarrays for relative gene expression analysis. Ying Wang et al. [44] perform a quality evaluation of two RNAseq datasets looking at chicken transcriptome gene representation. They focused on determining the optimal number of reads needed for detection of increasing percentages of annotated genes. Their study looked at sequencing read length coupled to the number of reads needed for optimal detection of both abundant and rare transcripts. Their work provides a useful, orderly approach to evaluating the level of RNAseq coverage needed for a given percent of gene detection in organisms other than human with well annotated genomes.

Markovets and Herman have developed a novel tool, Transcriptome Analysis with Circos, TrAC, for comparative analysis of RNAseq short-read data [45]. To validate TrAC, the authors selected the TCA and glycolysis pathways for comparison of normal brain and cancer RNAseq results. They calculated the expression level for a quantitative digital signal and visual output of the topology of transcript coverage. They showed unique expression patterns for pathway markers between normal and cancer samples as a way to characterize the drastic metabolic shifts in these pathways known as the Marberg effect. However, TrAC is not pathway specific and has broad application to gene expression-related biological questions.

\section{Imaging and structural biology}

Determining the effects of hypertension and related diseases on vascular structure is complicated by the difficulty of measuring arterial morphology non-invasively.
Diedrich et al.[46] computationally measured tortuosity, or twistedness, of arteries in Magnetic Resonance Angiography images. They were able to differentiate between hypertensive and non-hypertensive populations using arterial tortuosity measures thereby validating its use determining underlying arterial morphology.

In "An Improved Border Detection in Dermoscopy Images for Density Based Clustering" [47], the authors take their previously developed dermoscopic region classification method, DBSCAN, and improve a preprocessing step to have direct access to image information, and make use of color information (if present), with significant improvement in both speed and accuracy over the original DBSCAN.

A paper by Xiaofei Nan et al.[48] demonstrates a feasibility of splitting a problem domain into several nonoverlapping sub-problems to simplify learning tasks for biological predictions. The authors provide a metric to rank domain information attributes according to their potential to reduce the uncertainty of a classification task. In comparison with other methods this approach enhances prediction performance of the classifier.

\section{Miscellaneous}

Halil Bisgin et al. report a method to identify topics within pharmaceutical labels to compare their similarity in an automated, objective manner [49]. This helps enable identification of drugs with similar effects, safety concerns and adverse events. They find their method is accurate at grouping drugs in each of these capacities.

Stephen Winters-Hilt and colleagues [50] provide an overview of potential applications of NTD technology in biosensing. Applications include single nucleotide polymorphism (SNP) detection, targeted DNA re-sequencing, protein isoforms assays, and biosensing via antibody or aptamer couple molecules. They also describe a kit platform, the Nanoscope Kit, to increase the accessibility of the technology.

In "A Modified Stokes-Einstein Equation for A-beta Aggregation" [51], the authors argue that the standard Stokes-Einstein equation is insufficient to understand Abeta 42 protein diffusion, given its aggregation behavior, and demonstrate a modified form of the Stokes-Einstein equation with improved modeling performance.

\section{Future meetings}

The Inn at Ole Miss on the Campus of the University of Mississippi in Oxford, MS will be the site of MCBIOS 2012. The 2011-2012 MCBIOS President is Dr. Doris Kupfer of the Federal Aviation Administration. Dr. Edward Perkins of the US Army Engineer Research and Development Center is now the President-elect. MCBIOS is a regional affiliate of the International Society for Computational Biology (http://www.ISCB. 
org). For information regarding MCBIOS and our future meetings, see http://www.MCBIOS.org.

\begin{abstract}
Acknowledgements
We would like to thank the many anonymous peer reviewers who helped to ensure the quality of these Proceedings. EP was supported by the U.S. Army Environmental Quality Technology Research Program. Permission to publish this information was granted by the Chief of Engineers. SB was supported by the National Science Foundation under award number EPS 0903787. This article has been published as part of BMC Bioinformatics Volume 12 Supplement 10, 2011: Proceedings of the Eighth Annual MCBIOS Conference. Computational Biology and Bioinformatics for a New Decade. The full contents of the supplement are available online at http://www. biomedcentral.com/1471-2105/12?issue=S10.

Funding for this conference was made possible, in part, by the Food and Drug Administration through grant 1R13FD004229-01. The views expressed in written conference materials or publications and by speakers and moderators do not necessarily reflect the official policies of the Department of Health and Human Services; nor does any mention of trade names, commercial practices, or organization imply endorsement by the United States Government.
\end{abstract}

\section{Author details}

'Arthritis and Immunology Research Program, Oklahoma Medical Research Foundation; 825 N.E. 13th Street, Oklahoma City, OK 73104-5005, USA. ${ }^{2}$ Aerospace Medical Institute, Federal Aviation Administration, Oklahoma City, OK 73169, USA. ${ }^{3}$ US Army Engineer Research and Development Center, 3909 Halls Ferry Road, Vicksburg, MS 39180, USA. ${ }^{4}$ Department of Computer Science and Engineering, Mississippi State University, Box 9637, Mississippi State, MS 39762, USA. ${ }^{5}$ Computer Science Department, University of New Orleans, USA. 'Department of Electrical and Computer Engineering, Texas A\&M University, College Station, TX 77843-3128, USA.

\section{Author contributions}

All authors served as editors for these proceedings, with JDW serving as Senior Editor. All authors helped write this editorial.

\section{Competing interests}

The authors have no competing interests to declare.

Published: 18 October 2011

\section{References}

1. Ammari M, McCarthy FM, Nanduri B, Pinchuk LM: Analysis of Bovine Viral Diarrhea Viruses-infected monocytes: identification of cytopathic and non-cytopathic biotype differences. BMC Bioinformatics 2010, 11(Suppl 6): S9.

2. Su J, Yoon BJ, Dougherty ER: Identification of diagnostic subnetwork markers for cancer in human protein-protein interaction network. BMC Bioinformatics 2010, 11(Suppl 6):S8.

3. Zhou A, Zhang F, Chen JY: PEPPI: a peptidomic database of human protein isoforms for proteomics experiments. BMC Bioinformatics 2010, 11(Suppl 6):S7.

4. Xu J, Wise C, Varma V, Fang H, Ning B, Hong H, Tong W, Kaput J: Two new ArrayTrack libraries for personalized biomedical research. $B M C$ Bioinformatics 2010, 11(Suppl 6):S6.

5. Ding D, Xu L, Fang H, Hong H, Perkins R, Harris S, Bearden ED, Shi L, Tong W: The EDKB: an established knowledge base for endocrine disrupting chemicals. BMC Bioinformatics 2010, 11(Suppl 6):S5.

6. Fang $H$, Xu J, Ding D, Jackson $S A$, Patel IR, Frye JG, Zou W, Nayak R, Foley $S$, Chen J, et al: An FDA bioinformatics tool for microbial genomics research on molecular characterization of bacterial foodborne pathogens using microarrays. BMC Bioinformatics 2010, 11(Suppl 6):S4.

7. Melcher U: Assessing constancy of substitution rates in viruses over evolutionary time. BMC Bioinformatics 2010, 11(Suppl 6):S3.

8. Manda P, Freeman MG, Bridges SM, Jankun-Kelly TJ, Nanduri B, McCarthy FM, Burgess SC: GOModeler-a tool for hypothesis-testing of functional genomics datasets. BMC Bioinformatics 2010, 11(Suppl 6): S29.
9. Bottoms CA, Flint-Garcia S, McMullen MD: IView: introgression library visualization and query tool. BMC Bioinformatics 2010, 11(Suppl 6):S28.

10. Jia Y, Huan J: Constructing non-stationary Dynamic Bayesian Networks with a flexible lag choosing mechanism. BMC Bioinformatics 2010, 11(Suppl 6):S27.

11. Kockara S, Mete M, Chen B, Aydin K: Analysis of density based and fuzzy c-means clustering methods on lesion border extraction in dermoscopy images. BMC Bioinformatics 2010, 11(Suppl 6):S26.

12. Kelley RY, Gresham C, Harper J, Bridges SM, Warburton ML, Hawkins LK, Pechanova O, Peethambaran B, Pechan T, Luthe DS, et al: Integrated database for identifying candidate genes for Aspergillus flavus resistance in maize. BMC Bioinformatics 2010, 11(Suppl 6):S25.

13. Ghosh P, Kumar A, Datta B, Rangachari V: Dynamics of protofibril elongation and association involved in Abeta42 peptide aggregation in Alzheimer's disease. BMC Bioinformatics 2010, 11(Suppl 6):S24.

14. Mete M, Sirakov NM: Lesion detection in demoscopy images with novel density-based and active contour approaches. BMC Bioinformatics 2010, 11(Suppl 6):S23.

15. Di C, Xu W, Su Z, Yuan JS: Comparative genome analysis of PHB gene family reveals deep evolutionary origins and diverse gene function. $B M C$ Bioinformatics 2010, 11(Suppl 6):S22.

16. Koessler DR, Knisley DJ, Knisley J, Haynes T: A predictive model for secondary RNA structure using graph theory and a neural network. BMC Bioinformatics 2010, 11(Suppl 6):S21.

17. Kandoth C, Ercal F, Frank RL: A framework for automated enrichment of functionally significant inverted repeats in whole genomes. $B M C$ Bioinformatics 2010, 11(Suppl 6):S20.

18. Bai S, Du T, Khosravi E: Applying internal coordinate mechanics to model the interactions between $8 \mathrm{R}$-lipoxygenase and its substrate. BMC Bioinformatics 2010, 11(Suppl 6):S2.

19. Chaitankar V, Ghosh P, Perkins EJ, Gong P, Zhang C: Time lagged information theoretic approaches to the reverse engineering of gene regulatory networks. BMC Bioinformatics 2010, 11(Suppl 6):S19.

20. Smits SA, Ouverney CC: Phylometrics: a pipeline for inferring phylogenetic trees from a sequence relationship network perspective. BMC Bioinformatics 2010, 11(Suppl 6):S18.

21. Bland C, Newsome AS, Markovets AA: Promoter prediction in E. coli based on SIDD profiles and Artificial Neural Networks. BMC Bioinformatics 2010, 11(Suppl 6):S17.

22. Kumar R, Nanduri B: HPIDB-a unified resource for host-pathogen interactions. BMC Bioinformatics 2010, 11(Suppl 6):S16.

23. Quest DJ, Land ML, Brettin TS, Cottingham RW: Next generation models for storage and representation of microbial biological annotation. BMC Bioinformatics 2010, 11(Suppl 6):S15.

24. Tjioe E, Berry MW, Homayouni R: Discovering gene functional relationships using FAUN (Feature Annotation Using Nonnegative matrix factorization). BMC Bioinformatics 2010, 11(Suppl 6):S14.

25. Rawat A, Gust KA, Elasri MO, Perkins EJ: Quail Genomics: a knowledgebase for Northern bobwhite. BMC Bioinformatics 2010, 11(Suppl 6):S13.

26. Uzuner U, Shi W, Liu L, Liu S, Dai SY, Yuan JS: Enzyme structure dynamics of xylanase I from Trichoderma longibrachiatum. BMC Bioinformatics 2010, 11(Suppl 6):S12.

27. Halic T, Kockara S, Bayrak C, Rowe R: Mixed reality simulation of rasping procedure in artificial cervical disc replacement (ACDR) surgery. BMC Bioinformatics 2010, 11(Suppl 6):S11.

28. Wen Z, Wang C, Shi Q, Huang Y, Su Z, Hong H, Tong W, Shi L: Evaluation of gene expression data generated from expired Affymetrix GeneChip(R) microarrays using MAQC reference RNA samples. BMC Bioinformatics 2010, 11(Suppl 6):S10.

29. Mayo ML, Perkins EJ, Ghosh P: Diffusion-Reaction in a One-Dimensional Uncorrelated Random Environment: Application to Protein Transport Along DNA. BMC Bioinformatics 2011, 12(Suppl 10):S18.

30. Roy S, Heinrich K, Phan V, Berry MW, Homayouni R: Latent Semantic Indexing of PubMed abstracts for identification of transcription factor candidates from microarray derived gene sets. BMC Bioinformatics 2011, 12(Suppl 10):S19.

31. Matthews SJ, Williams TL: An Efficient and Extensible Approach for Compressing Phylogenetic Trees. BMC Bioinformatics 2011, 12(Suppl 10):S16.

32. Li Y, Gong P, Perkins EJ, Zhang C, Wang N: RefNetBuilder: A Platform for Construction of Integrated Reference Gene Regulatory Networks from Expressed Sequence Tags. BMC Bioinformatics 2011, 12(Suppl 10):S20. 
33. Ghaffari N, Ivanov I, Qian X, Doughtery ER: A CoD-based Stationary Control Policy for Intervening in Large Gene Regulatory Networks. BMC Bioinformatics 2011, 12(Suppl 10):S10.

34. Esfahani MS, Yoon B-J, Doughtery ER: Probabilistic reconstruction of the tumor progression process in gene regulatory networks in the presence of uncertainty. BMC Bioinformatics 2011, 12(Suppl 10):S9.

35. Zhang F, Chen JY: HOMER: A Human Organ-specific Molecular Electronic Repository. BMC Bioinformatics 2011, 12(Suppl 10):S4.

36. Qian X, Sahraeian SME, Yoon B-J: Enhancing the accuracy of HMM-based conserved pathway prediction using global correspondence scores. BMC Bioinformatics 2011, 12(Suppl 10):S6.

37. Swamy MV, Liu Z, Gou L, Su Z, Ye Y, Fang H, Ding D, Tong W, Xu X: Constructing a robust protein-protein interaction network by integrating multiple public databases. BMC Bioinformatics 2011, 12(Suppl 10):S7.

38. Griffith SD, Quest DJ, Brettin TS, Cottingham RW: Scenario Driven Data Modelling: A Method for Integrating Diverse Sources of Data and Data Streams. BMC Bioinformatics 2011, 12(Suppl 10):S17.

39. Dozmorov MG, Wren JD: High-throughput processing and normalization of one-color microarrays for transcriptional meta-analyses. BMC Bioinformatics 2011, 12(Suppl 10):S2.

40. Dozmorov MG, Giles CB, Wren JD: Global meta-analysis of 1-color microarray experiments accurately predicts gene ontology categories. BMC Bioinformatics 2011, 12(Suppl 10):S14

41. Wren JD: A global meta-analysis of microarray expression data to predict unknown gene functions and estimate the literature-data divide. Bioinformatics 2009, 25(13):1694-1701.

42. Daum JR, Wren JD, Daniel JJ, Sivakumar S, McAvoy JN, Potapova TA Gorbsky GJ: Ska3 is required for spindle checkpoint silencing and the maintenance of chromosome cohesion in mitosis. Curr Biol 2009, 19(17):1467-1472.

43. Chen M, Shi L, Kelly R, Perkins $R$, Fang $H$, Tong W: Selecting a single model or combining multiple models for microarray-based classifier development? - A comparative analysis based on large and diverse datasets generated from the MAQC-II project. BMC Bioinformatics 2011, 12(Suppl 10):S3

44. Wang $Y$, Ghaffari $N$, Johnson CD, Braga-Neto UM, Wang $H$, Chen $R$, Zhou $H$ : Evaluation of coverage and depth of transcriptome by RNA-Seq in chickens. BMC Bioinformatics 2011, 12(Suppl 10):S5.

45. Markovets AA, Herman D: Analysis of cancer metabolism with highthroughput technologies. BMC Bioinformatics 2011, 12(Suppl 10):S8.

46. Diedrich KT, Roberts JA, Schmidt RH, Kang C-K, Cho Z-H, Parker DL: Validation of an Arterial Tortuosity Measure with Application to Hypertension. BMC Bioinformatics 2011, 12(Suppl 10):S15.

47. Suer S, Kockara S, Mete M: An Improved Border Detection in Dermoscopy Images for Density Based Clustering. BMC Bioinformatics 2011, 12(Suppl 10):S12.

48. Nan X, Fu G, Zhao Z, Liu S, Patel RY, Liu H, Daga PR, Doerksen RJ, Dang X, Chen $Y$, et al: Leveraging Domain Information to Restructure Biological Prediction. BMC Bioinformatics 2011, 12(Suppl 10):S22.

49. Bisgin $H$, Liu Z, Fang $H, X u X$, Tong W: Mining FDA drug labels using an unsupervised learning technique - topic modeling. BMC Bioinformatics 2011, 12(Suppl 10):S11.

50. Winters-Hilt S, Morales E, Horton-Chao E: The NTD Nanoscope: Potential Applications and Implementations. BMC Bioinformatics 2011, 12(Suppl 10): \$21.

51. Achuthan S, Chung BJ, Ghosh P, Rangachari V, Vaidya A: A Modified Stokes-Einstein Equation for A beta Aggregation. BMC Bioinformatics 2011, 12(Suppl 10):S13

doi:10.1186/1471-2105-12-S10-S1

Cite this article as: Wren et al:: Proceedings of the 2011 MidSouth

Computational Biology and Bioinformatics Society (MCBIOS)

Conference. BMC Bioinformatics 2011 12(Suppl 10):S1.

\section{Submit your next manuscript to BioMed Central and take full advantage of:}

- Convenient online submission

- Thorough peer review

- No space constraints or color figure charges

- Immediate publication on acceptance

- Inclusion in PubMed, CAS, Scopus and Google Scholar

- Research which is freely available for redistribution 